\title{
The impact of the implementation of bundle in the prevention of ventilator-associated pneumonia in intensive care units
}

\author{
DP Cais ${ }^{*}$, R Mourão
}

From International Conference on Prevention \& Infection Control (ICPIC 2011)

Geneva, Switzerland. 29 June - 2 July 2011

\section{Introduction / objectives}

Ventilator-associated pneumonias (VAP) are the most prevalent infections in intensive care units (ICU). To reduce this rate, it is recommended the application of bundles - groups of individual practices that result in substantial improved care.

\section{Aim}

To measure the adherence to VAP bundle, correlating with the incidence of VAP per 1000 days of mechanical ventilation (MV).

\section{Methods}

The study was conductedin three general ICU (adult, cardiology and pediatric) of a medium sized hospital in Sao Paulo (Brazil) from June/2009 to April/2010. All patients on MV were assessed using a check list with five key measures: physiotherapy, presence of condensate in the circuit, a high head $>30^{\circ}$, oral hygiene with chlorhexidine and manual resuscitator individual. The visits were carried out fortnightly, without notice, by the same researcher, with subsequent calculation of compliance.

\section{Results}

At the beginning, the incidence of VAP was 20/1000 days of MV and the adherence to the measures was $15 \%$. In the second month, the membership had increased gradually, inversely proportional to the rate of VAP. From September to December, adherence ranged from 40 to $70 \%$, with rates of VAP from 5 to $15 / 1000$ days of MV. In February, there was a peak (30/1000

Infection Control, Hospital Samaritano, São Paulo, Brazil days of $\mathrm{MV}$ ) and good adhesion to the bundle (70\%), which may reflect the increase of patient severity. Later, the Infection Control Team developed an educational work, resulting in significant decrease in VAP rate (8/ 1000 days of MV) and $90 \%$ adherence to the bundle.

\section{Conclusion}

The application bundle is a feasible reality that produces good results in nosocomial infection rates. However, education and periodic training remain a fundamental process of improving health services.

\section{Disclosure of interest}

None declared.

Published: 29 June 2011

doi:10.1186/1753-6561-5-S6-P70

Cite this article as: Cais and Mourão: The impact of the implementation of bundle in the prevention of ventilator-associated pneumonia in intensive care units. BMC Proceedings 2011 5(Suppl 6):P70.

Submit your next manuscript to BioMed Central and take full advantage of:

- Convenient online submission

- Thorough peer review

- No space constraints or color figure charges

- Immediate publication on acceptance

- Inclusion in PubMed, CAS, Scopus and Google Scholar

- Research which is freely available for redistribution 